Article

\title{
Hierarchical coculture of hepatocyte and hepatic non- parenchymal cells for liver fibrosis studies in vitro
}

\author{
Qiao You Lau 1,2, , Fuad Gandhi Torizal 2,3, Marie Shinohara 1, and Yasuyuki Sakai 1, 2,3 \\ 1 Institute of Industrial Science, The University of Tokyo, Tokyo, Japan; QLAU001@e.ntu.edu.sg (Q.Y.L), \\ marie-s@iis.u-tokyo.ac.jp (M.S.), sakaiyasu@chemsys.t.u-tokyo.ac.jp (Y.S.) \\ 2 Department of Bioengineering, Graduate School of Engineering, The University of Tokyo, Tokyo, Japan; \\ QLAU001@e.ntu.edu.sg (Q.Y.L), t_gandhi@chemsys.t.u-tokyo.ac.jp (F.G.T), sakaiyasu@chemsys.t.u- \\ tokyo.ac.jp (Y.S.) \\ 3 Department of Chemical System Engineering, Graduate School of Engineering, The University of Tokyo, \\ Tokyo, Japan; t_gandhi@chemsys.t.u-tokyo.ac.jp (F.G.T), sakaiyasu@chemsys.t.u-tokyo.ac.jp (Y.S.) \\ * Correspondence: QLAU001@e.ntu.edu.sg ; Tel.: +81-5841-7073
}

\begin{abstract}
During chronic liver injury, inflammation leads to the development of liver fibrosisparticularly due to the activation of hepatic stellate cells (HSCs). However, the involvement of inflammatory cytokines in HSC activation is unclear. Many existing in vitro liver models do not include these non-parenchymal cells (NPCs), and hence, do not represent the physiological relevance found in vivo. Herein, we demonstrated the hierarchical coculture of primary rat hepatocytes with NPCs such as the human-derived HSC line (LX-2) and the human-derived liver sinusoidal endothelial cell line (TMNK-1). The coculture tissue had higher albumin production and hepatic cytochrome P450 3A4 activity compared to the monoculture. We then further studied the effects of stimulation by both oxygen tension and key pro-fibrogenic cytokines, such as the transforming growth factor beta (TGF- $\beta$ ), on HSC activation. Gene expression analysis revealed that lower oxygen tension and TGF- $\beta 1$ stimulation enhanced collagen type I, III, and IV, alpha-smooth muscle actin, platelet-derived growth factor, and matrix metallopeptidase expression from LX-2 cells in the hierarchical coculture after fibrogenesis induction. This hierarchical in vitro cocultured liver tissue could, therefore, provide an improved platform as a disease model for elucidating the interactions of various liver cell types and biochemical signals in liver fibrosis studies.
\end{abstract}

Keywords: liver fibrosis; hepatic stellate cells; coculture; transforming growth factor beta; oxygen tension

\section{Introduction}

Liver fibrosis is a common pathological outcome of several chronic liver diseases, such as viral hepatitis, and results from extracellular matrix (ECM) accumulation following hepatic stellate cell (HSC) activation and proliferation [1], which gives them pro-inflammatory and fibrogenic properties [2]. Despite the high prevalence and detrimental outcomes, many current treatments are restricted to relieving chronic stresses, and no effective therapies are available [3,4]. Therefore, researchers are challenged to reveal the detailed mechanisms of liver fibrosis and to develop efficient drugs for clinical treatment. Animal testing is still the most common preclinical assessment mode, but sometimes, there is poor prognostic value regarding both efficacy and toxicity in terms of the human physiological response $[5,6]$. Furthermore, there are many ethical concerns about the use of animal models [5].

Primary hepatocytes have been commonly utilized for the generation of in vitro hepatocyte models to illuminate the liver processes in drug metabolism and toxicity. However, hepatocyte functions are compromised and, therefore, are far from recapitulating liver tissues' functions because of the rapid de-differentiation and short-term survival of in vitro cultured hepatocytes, limiting the 
generation of functional engineered liver tissues [7]. As a liver fibrosis model in vitro, hypoxia has been considered a stress factor that may lead to the activation of HSCs [8], and HSC monocultures have been evaluated by stimulation with various pro-fibrotic and pro-inflammatory cytokines to enable the investigation of how the inflammation-driven complex microenvironment affects HSC activation and fibrosis development [1,9]. However, the interactions between hepatocytes and HSCs could not be observed in monocultures (e.g., The pro-inflammatory factor secretion from hepatocytes enhances HSC activation, resulting in excess collagen fiber produced by activated HSCs and myofibroblasts, which interferes with hepatic functions). The lack of robust and biologically relevant liver fibrosis in vitro models for functional pharmacokinetics and toxicological studies poses a significant problem associated with the development of effective therapies [10-12], as many of these models focus only on the parenchymal hepatocytes or non-parenchymal cells (NPCs) [13] while overlooking interactions from the surrounding hepatic cells [14]. Consequently, stable cocultured liver tissue formation for liver fibrosis studies is desired.

The long-term behavior of hepatocytes might be modulated by heterotypic cell-cell interactions in engineered tissues [7], and it is widely known that coculturing with NPCs could improve the microenvironments of cells [15,16], hence assisting in stabilizing the phenotype of hepatocytes [14]. Nonetheless, many difficulties emerged when establishing a functional liver tissue culture system. $\mathrm{Du}$ et al. reported that hepatocyte, HSC, LSEC, and Kupffer cell coculture in a microfluidic device enhanced hepatic function. Even though they achieved hierarchical structure formation, cell-cell interaction between hepatocytes was lost [17]. Instead, Xiao et al. developed an in vitro liver-like tissue coculture system and demonstrated that direct oxygenation through the polydimethylsiloxane (PDMS) membranes permitted the organization of hierarchical layers of primary rat hepatocytes and human liver sinusoidal endothelial cell line (TMNK-1), which could prove to be useful in comprehensive studies of cell signaling pathways between parenchymal and non-parenchymal cells and the understanding of heterotypic cell-cell interactions critical for functionalities of the liver [14]. Thus, the direct incorporation of NPCs such as HSCs and liver sinusoidal endothelial cells (LSECs) in in vitro liver platforms is vital for emulating the functions of the liver to establish a tissue-specific and physiologically relevant model for the study of liver fibrosis, which could lead to efficient novel drug development and a more accurate prediction of the functional and safety drug dosage.

In this study, we aim to develop an in vitro liver tissue to simulate an in vivo-like liver tissue physiology by a hierarchical coculture of both the parenchymal rat hepatocytes and NPCs - HSCs and LSECs. Also, we characterized the response of HSCs to activation by varying the physiological parameters, such as oxygen concentration and exposure to the well-known pro-fibrogenic mediator, TGF- $\beta$ [18]. We hypothesized that this coculture system would be able to respond to the fibrogenic effects due to these stimulations and could, therefore, be used to study liver fibrosis in vitro.

\section{Materials and Methods}

\subsection{Rat hepatocyte isolation}

Primary hepatocytes were isolated from 7-8-week-old male Wistar rats (Sankyo Laboratory, Japan) by a two-step collagenase perfusion technique [19] and suspended in ice-cold seeding Williams' E Medium (Gibco, Japan). All animals were treated in accordance with the University of Tokyo guidelines for animal experiments and following the guidelines of the Japanese Ministry of Education.

\subsection{Hepatocyte monoculture}

Isolated primary rat hepatocytes were seeded at a density of $1.0 \times 10^{5} \mathrm{cells} / \mathrm{cm}^{2}$ on PDMS plates to form a confluent monolayer on day -3 . The Williams' Medium E was supplemented with $0.1 \mu \mathrm{M}$ dexamethasone (Wako, Japan), $10 \mathrm{ng} / \mathrm{ml}$ mouse epidermal growth factor (EGF) (Takara, Japan), 0.5 $\mathrm{mM}$ ascorbic acid 2-phosphate (Wako, Japan), 1\% GlutaMAX-I (Gibco, Japan), 1\% InsulinTransferrin-Selenium (ITS-G) (Gibco, Japan), 15 mM HEPES (STAR Chemical, Japan), and 1\% antibiotic and antimycotic solution consisting of penicillin, streptomycin, and amphotericin B (Wako, 
Japan). Hepatocytes were cultured in a humidified incubator at $37^{\circ} \mathrm{C}$ in a $10 \% \mathrm{O}_{2}$ and $2.5 \% \mathrm{O}_{2}$ atmosphere up to day 14 , with medium replacement performed every other day.

\subsection{Hepatic non-parenchymal cell culture}

LX-2, a human-derived hepatic stellate cell (HSC) line, was maintained in Dulbecco's modified eagle's medium (DMEM) high glucose basal media (Wako, Japan) supplemented with $10 \%$ fetal bovine serum (FBS) (Gemini Bio-Products, Japan), 1\% GlutaMAX-I (Gibco, Japan), and 1\% antibiotic and antimycotic solution consisting of penicillin/streptomycin (P/S) and amphotericin B (Wako, Japan). TMNK-1, a human-derived liver sinusoidal endothelial cell (LSEC) line, was maintained in MCDB 131 medium (Gibco, Japan), supplemented with endothelial cell growth medium-2 singlequots supplements (Lonza, Japan) with the exclusion of GA-1000. This was further supplemented with $1 \%$ antibiotic and antimycotic solution consisting of $\mathrm{P} / \mathrm{S}$ and amphotericin $\mathrm{B}$ (Wako, Japan). The respective culture medium was changed every two days, and the cells were passaged at approximately $80 \%$ confluency.

\subsection{Coculturing hepatocytes with hepatic non-parenchymal cells}

On day -3 , rat hepatocytes were seeded at a density of $1.0 \times 10^{5}$ cells $/ \mathrm{cm}^{2}$ to form a confluent monolayer in pretreated 24-well or 96-well polydimethylsiloxane (PDMS) plates (Vessel, Japan), which facilitate direct oxygenation of cells by diffusion through PDMS membranes that could maintain cell viability and function [20] (Figure 1). PDMS surfaces were treated with oxygen plasma for $60 \mathrm{~s}$ using the YHS-GZA 200 (SAKIGAKE-Semiconductor, Japan) and coupled with (3mercaptopropyl)-trimethoxysilane (TCI, Japan). The introduced amino groups were reacted with a cross-linker, N-(4-maleimidobutyryloxy)-succinimide (GMBS) (Dojindo, Japan), and subsequently activated by 1-ethyl-3-(3-dimethylaminopropyl)-carbodiimide, hydrochloride (WSC) (Dojindo, Japan), and N-hydroxysulfosuccinimide sodium salt (sulfo-NHS) (TCI, Japan). Finally, the PDMS surfaces were coated with collagen type I-P (Nitta Gelatin, Japan) to facilitate cell attachment.

On day -2 , LX-2 cells were seeded onto rat hepatocytes at a density of $5.0 \times 10^{3} \mathrm{cells} / \mathrm{cm}^{2}$. On day -1 , TMNK-1 cells were seeded onto the cocultures at a density of $1.0 \times 10^{5} \mathrm{cells} / \mathrm{cm}^{2}$. The hierarchical cocultures were then cultured for one day. They were cultured in a humidified incubator at $37^{\circ} \mathrm{C}$ in $5 \% \mathrm{CO}_{2}$ and $20 \% \mathrm{O}_{2}$. The monoculture condition, in which only rat hepatocytes were cultured, was tested to confirm the hepatic function of hepatocytes. Culture medium was changed every two days with Williams' Medium E containing $0.1 \mu \mathrm{M}$ dexamethasone (Wako, Japan), $10 \mathrm{ng} / \mathrm{ml}$ mouse epidermal growth factor (EGF) (Takara, Japan), $0.5 \mathrm{mM}$ ascorbic acid 2-phosphate (Wako, Japan), 1\% GlutaMAX-I (Gibco, Japan), 1\% Insulin-Transferrin-Selenium (ITS-G) (Gibco, Japan), 15 mM HEPES (STAR Chemical, Japan), and $1 \%$ antibiotic and antimycotic solution consisting of penicillin, streptomycin, and amphotericin B (Wako, Japan).

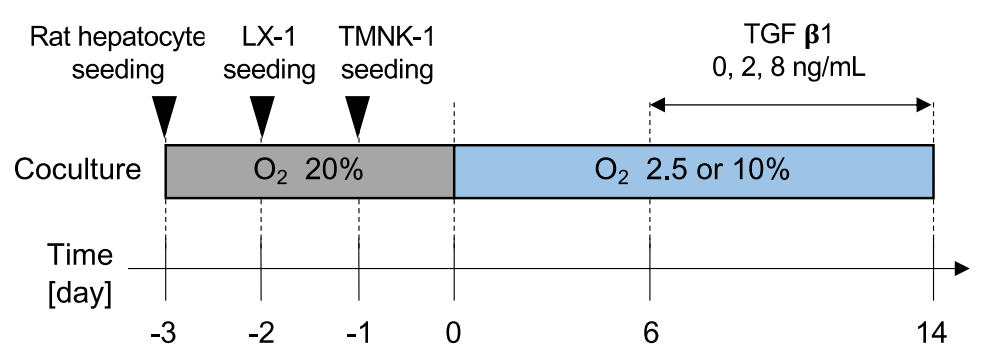

Figure 1. Experimental schedule of coculture and stimulation by TGF- $\beta 1$.

\subsection{Fibrogenesis induction under hypoxia and exposure to cytokines}

From day 0 onward, oxygenation conditions were varied from hyperoxic tension of $20 \%$ to $10 \%$ physiological oxygenation level and $2.5 \%$ hypoxic condition [21]. Fibrogenesis was further induced on day 6 with the pro-fibrogenic cytokine, TGF- $\beta 1$, at 2 and $8 \mathrm{ng} / \mathrm{ml}$ until day 14, which marked the end of the experiment. 


\subsection{Measurement of albumin production}

The culture supernatant was collected, and the amount of albumin secreted in the culture medium was determined using the sandwich-type enzyme-linked immunosorbent assay (ELISA) [22]. Goat anti-rat albumin antibody (Bethyl, USA) was used as the primary antibody and a horseradish peroxidase-conjugated sheep anti-rat albumin (Bethyl, USA) was used as the secondary antibody. The absorbance was measured by the microplate reader iMark (Bio-Rad, USA) at $490 \mathrm{~nm}$ with an optical correction of $630 \mathrm{~nm}$.

\subsection{Cytochrome P450 (CYP) 3 A4 activity assay}

Rat CYP3A4 activity was determined on day 6 and day 14 of the culture using the P450-Glo CYP3A4 assay kit (Promega, USA). Williams' Medium E was aspirated from cultured wells, and fresh Williams' Medium E containing Luciferin-3A4 (1:1000) was added to the wells and incubated for $1 \mathrm{~h}$ in a $37^{\circ} \mathrm{C}$ incubator at their respective oxygen tension. $25 \mu \mathrm{l}$ of culture medium containing metabolite from each well was transferred to opaque 96-well white luminometer plates, and $25 \mu 1$ of Luciferin Detection Reagent was added to initiate a luminescent reaction. Plates were incubated at room temperature for $20 \mathrm{~min}$ away from light, and the luminescence was subsequently read using the Wallac 1420 ARVO SX microplate luminometer (PerkinElmer, USA).

\subsection{Real-time quantitative polymerase chain reaction}

Total RNAs were isolated from tissue culture samples using the TRIzol reagent (Life Technologies, USA) and purified using the Direct-zol RNA MiniPrep kit (Zymo Research, USA) according to the manufacturer's instructions. The concentration and quality of each RNA sample were assessed with the BioSpec-nano spectrophotometer (Shimadzu, Japan). Complementary DNAs (cDNAs) were reverse-transcribed from $100 \mathrm{ng}$ total RNA samples using the ReverTra Ace qPCR RT Master Mix with gDNA Remover (Toyobo, Japan) protocol employing these phases: $37^{\circ} \mathrm{C}, 15 \mathrm{~min}$; $50^{\circ} \mathrm{C}, 5 \mathrm{~min} ; 98^{\circ} \mathrm{C}, 5 \mathrm{~min}$; and $4^{\circ} \mathrm{C}$, hold. Real-time quantitative polymerase chain reaction (qRTPCR) assays were then performed with the THUNDERBIRD SYBR qPCR mix (Toyobo, Japan) and assessed using the real-time StepOnePlus qPCR system (Applied Biosystems, USA) employing the following cycling conditions: pre-denaturation at $95^{\circ} \mathrm{C}$ for $60 \mathrm{~s}$, denaturation at $95^{\circ} \mathrm{C}$ for $15 \mathrm{~s}$, and extension (40 cycles) at $60^{\circ} \mathrm{C}$ for $60 \mathrm{~s}$. Primer sequences used for the real-time qPCR are shown in Table 1, with human and rat $\beta$-actin serving as the internal controls.

Table 1. List of qRT-PCR primers.

\begin{tabular}{|c|c|c|c|}
\hline Species & Gene & Forward Primer Sequensces & Reverse Primer Sequences \\
\hline \multirow{9}{*}{ Human } & $\boldsymbol{\beta}$-actin & ССTCATGAAGATCCTCACCGA & TTGCCAATGGTGATGACCTGG \\
\hline & a-SMA & AGGCACCCCTGAACCCCAA & CAGCACCGCCTGGATAGCC \\
\hline & Col1A1 & ССАААTСTGTСTСCСCAGAA & TCAAAAACGAAGGGGAGATG \\
\hline & Col3A1 & TGGTCTGCAAGGAATGCCTGGA & TCTTTCCCTGGGACACCATCAG \\
\hline & Col4A1 & CCTGGCTTGAAAAACAGCTC & СCCTGCTGAGGTCTGTGAAC \\
\hline & PDGF & ATGATCTCCAACGCCTGC & TCAGCAATGGTCAGGGAAC \\
\hline & TIMP1 & CAAGATGTATAAAGGGTTCCAAGC & TCCATCCTGCAGTTTTCCAG \\
\hline & MMP2 & AAGTATGGCTTCTGCCCTGA & ATTTGTTGCCCAGGAAAGTG \\
\hline & CTGF & AATGCTGCGAGGAGTGGGT & CGGCTCTAATCATAGTTGGGTCT \\
\hline \multirow{3}{*}{ Rat } & $\boldsymbol{\beta}$-actin & AGAGAAGCTGTGCTATGTTGC & GTACTCCTGCTTGCTGATCC \\
\hline & CYP1A1 & GATGCTGAGGACCAGGAAGACCGC & CAGGAGGCTGGACGAGAATGC \\
\hline & CYP1A2 & CTTGGAGAAGCGTGGCCAGG & CTACAAAGACAACGGTGGTCT \\
\hline
\end{tabular}




\subsection{Vertical cross-section, HEE staining, AZAN staining, and immunostaining}

Cell-loaded PDMS discs were collected and fixed with $4 \%$ paraformaldehyde solution (FUJIFILM Wako Pure Chemical, Japan) in PBS overnight, and the cell sheets on the PDMS membranes were rinsed thoroughly with PBS. Fixed samples were dehydrated and then embedded in paraffin. Vertical sections of $5 \mathrm{~mm}$ thickness were cut off, deparaffinized, rehydrated, and stained with hematoxylin and eosin ( $\mathrm{H} \& \mathrm{E}$ ) or azocarmine and aniline blue (AZAN). In $\mathrm{H}$ and $\mathrm{E}$ staining, nuclei were stained deep blue-purple with hematoxylin, while the extracellular matrix and cytoplasm were stained in varying degrees of pink with eosin. In AZAN staining, nuclei and cytoplasm were stained red with azocarmine $G$, and collagen was stained blue with aniline blue, respectively. These histological vertical cross-sections were prepared and stained by Genostaff Co., Ltd. (Tokyo, Japan). Images were captured using a transmitted light microscope BX50 (Olympus, Japan).

For the immunostaining, tissue samples were fixed with $4 \%$ paraformaldehyde (PFA) (Wako, Japan) at room temperature for $30 \mathrm{~min}$ and washed with PBS thoroughly to remove the PFA. The $1 \%$ Triton X-100 (Wako, Japan) was added and incubated for $30 \mathrm{~min}$ for permeabilization. After washing with PBS, tissue samples were further incubated with a gelatin blocking buffer for $1 \mathrm{~h}$, followed by incubation with mouse anti-human alpha smooth muscle actin ( $\alpha$-SMA) monoclonal antibody (1:1000; Agilent Dako, USA) and goat anti type I collagen antibody (1:1000; SouthernBiotech, USA) overnight at $4^{\circ} \mathrm{C}$. Samples were washed with PBS and subsequently incubated with donkey anti mouse IgG H\&L (Alexa Fluor ${ }^{\circledR} 488$ ) antibody (1:100; Invitrogen, USA), and donkey anti goat IgG H\&L (Alexa Fluor ${ }^{\circledR}$ 647) antibody (1:100; Invitrogen, USA) for $1 \mathrm{~h}$ at room temperature while protected from light. After washing with PBS, samples were counterstained with 4',6-diamidino-2phenylindole (DAPI) (1:1000) (Dojindo, Japan) for $15 \mathrm{~min}$ and washed again with PBS. Fluorescent images were taken using a confocal laser scanning microscope FLUOVIEW FV3000 (Olympus, Japan).

\subsection{Statistical analysis}

Data are represented as the mean \pm standard deviation (SD). The student's two-tailed t-test was performed for the statistical analysis of albumin production, CYP3A4 activity, and gene expressions. A $p$-value below 0.05 was considered statistically significant.

\section{Results}

3.1. Hierarchical coculture structure was intact for two weeks and acquired better functionalities than hepatocyte monoculture

Rat hepatocyte, LX-2, and TMNK-1 were seeded layer by layer on an oxygen-permeable plate with a polydimethylsiloxane (PDMS) membrane surface (Figure 1). The hierarchical cocultured liver tissue consisting of LX-2 and TMNK-1 was cultured up to day 14 without detachment, whereas hepatocyte monocultures started to detach from the PDMS surface from about day 4 onward (SI Figure S1). This suggested that the coculture system had promoted cell-cell interaction and enhanced stability of cocultured liver tissues.

Albumin secretion in cocultures at both $10 \%$ and $2.5 \%$ oxygenation conditions was higher than monocultures for the entire culture period of 14 days (SI Figure S2A and S2B). As for the cocultures at $2.5 \%$ oxygenation condition, albumin secretion reached the maximum on day 8 , and then it rapidly decreased (SI Figure S2A). At 10\% oxygenation condition, albumin secretion reached the maximum on day 12 and maintained that high production level until day 14 (SI Figure S2B). By the end of day 14 , the cocultures in $10 \%$ oxygenation level had an albumin protein secretion level of about 1.8-fold higher than that of hepatocyte monocultures (SI Figure S2B), and cocultures in $2.5 \%$ oxygenation level had an albumin protein secretion level of about 2.1-fold higher than that of hepatocyte monocultures (SI Figure S2A). 
The hepatic cytochrome P450 (CYP) 3A4 activities of cell line cocultures were also higher in comparison to hepatocyte monocultures on day 6 (SI Figure S2C). Then, we proceeded to use the cocultured liver tissue for inflammation studies.

\subsection{Hypoxia-induced inflammation and elaborate gene expression}

Although no morphological changes were observed between the cocultures in $2.5 \%$ and $10 \%$ oxygenation conditions, a thicker tissue was formed under a $10 \%$ oxygen tension, as shown in the HE and AZAN histological staining (Figure 2A, SI Figure S1 and S3).

(A)

0

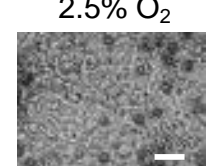

TGF- 1 $(\mathrm{ng} / \mathrm{mL})$

2

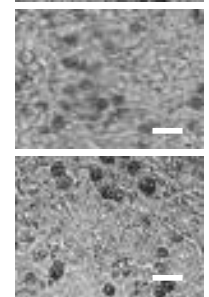

$10 \% \mathrm{O}_{2}$

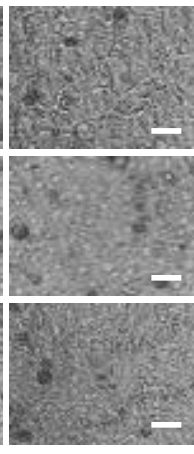

Scale $20 \propto m$
(B)

0

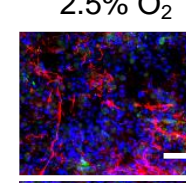

TGF- 1 $(\mathrm{ng} / \mathrm{mL})$
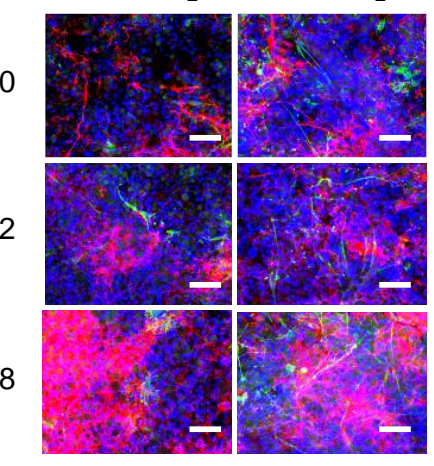

Scale $100 \circ \mathrm{m}$

Figure 2. Morphologies of coculture on day 14. (A) Phase-contrast images. (B) Immunostaining images. Green, red, and blue are a-SMA, collagen type I, and DAPI, respectively.

Albumin secretion gradually decreased when the cocultured liver tissues were subjected to a $2.5 \%$ hypoxic condition (SI Figure S2A and S2B). In the comparison of cocultures under different oxygen tensions, cocultures in $2.5 \%$ oxygen tension had an albumin protein secretion level of about 1.7-fold lower than that of the cocultures in 10\% oxygenation level on day 14 (Figure 3A). Moreover, the cocultures in $2.5 \%$ oxygenation condition exhibited about 6 -fold and 3 -fold higher CYP3A4 activity than $10 \%$ oxygenation condition on day 6 and day 14, respectively (SI Figure 2C and Figure 3B).

(A)

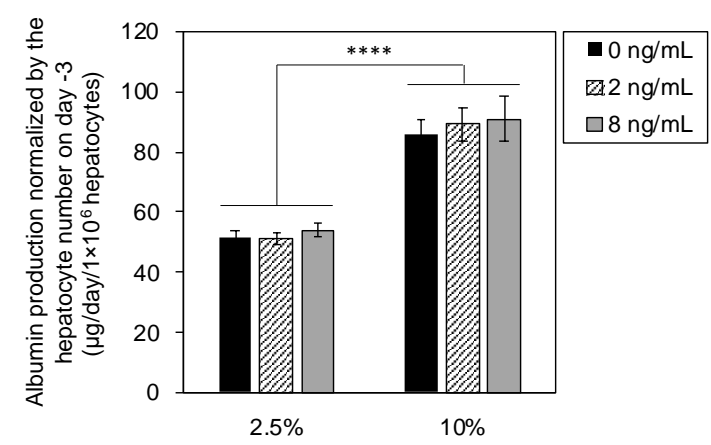

(B)

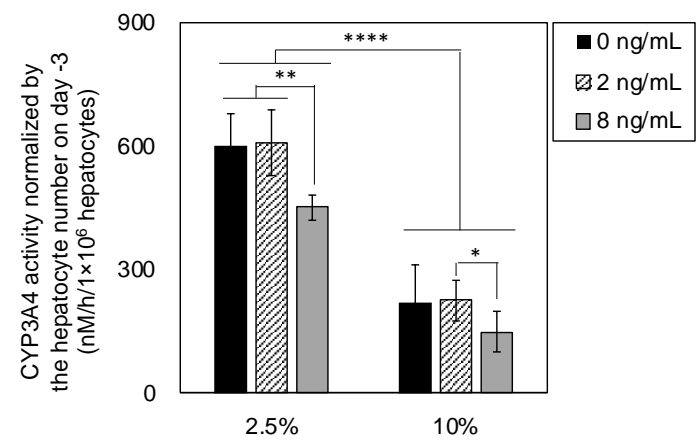

Figure 3. Evaluation of hepatic function in $2.5 \%$ and $10 \%$ oxygen tension with TGF- $\beta 1$ stimulation $(0,2,8 \mathrm{ng} / \mathrm{mL}$ ) on day 14 . (A) Albumin production in $2.5 \%$ and $10 \%$ oxygen tension. Data represent the mean \pm standard deviation $(\mathrm{SD}, \mathrm{n}=6)$ from two independent experiments. Each value was normalized to hepatocyte number on day -3 . Statistical significance was determined by the student's t-test with statistical significance of ${ }^{*} p<0.05,{ }^{* *} p<0.01,{ }^{* * *} p<0.001$, and ${ }^{* * * *} p<0.0001$. 
To investigate the impact of hypoxia on inducing inflammation and possible fibrogenesis, we measured the relative gene expression of HSC activation-related and fibrosis-related biomarkers on both day 6 and day 14. Gene expression of several biomarkers showed slight upregulation in 2.5\% compared to $10 \%$ oxygenation condition on day 6 (SI Figure S2D), although these increases in gene expression were not observed on day 14, except for the alpha-smooth muscle actin ( $\alpha$-SMA) and connective tissue growth factor (CTGF) biomarkers (Figure 4).

(A)

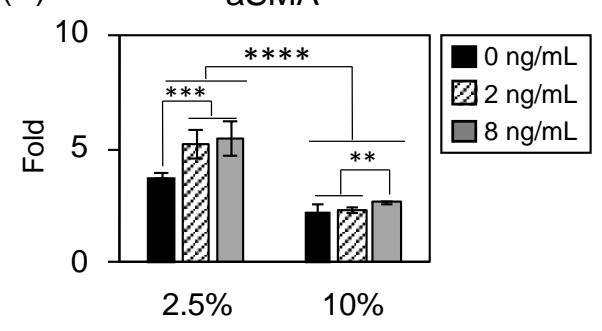

(C)

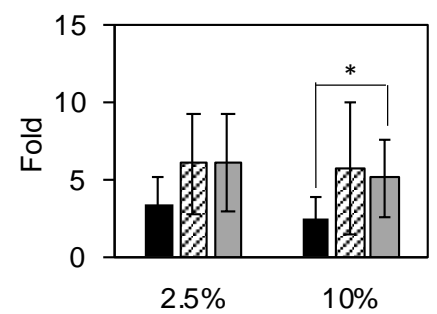

(E)

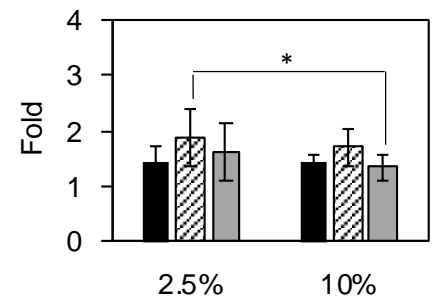

(G)

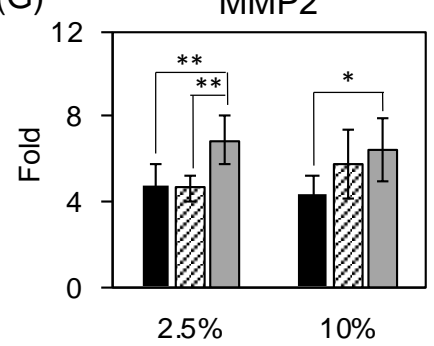

(I)
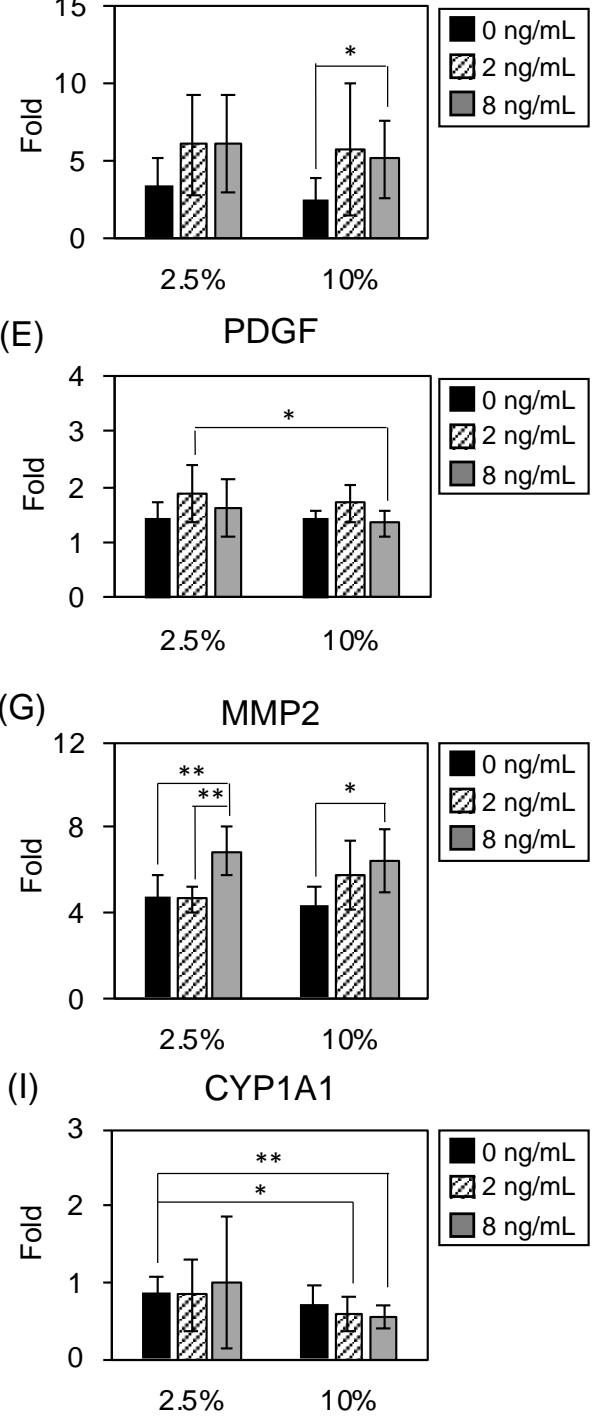

(B)

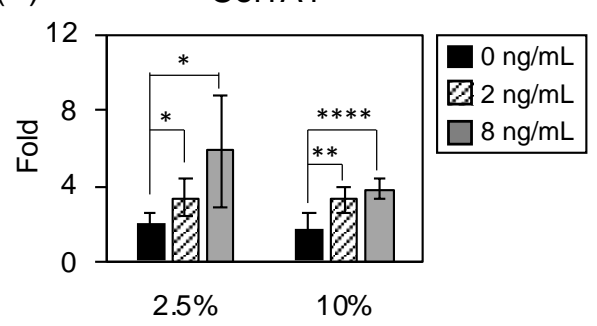

(D)

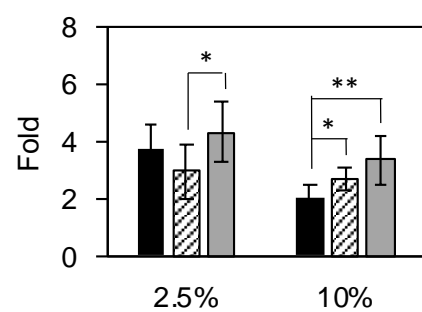

$(\mathrm{F})$

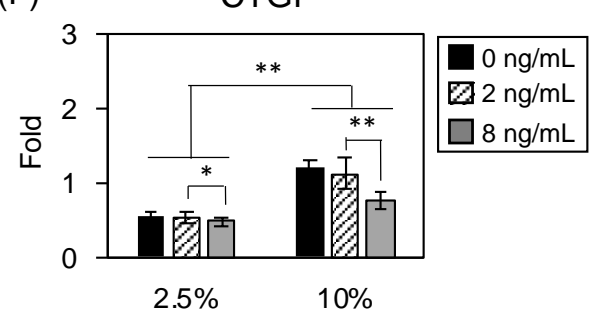

$(\mathrm{H})$

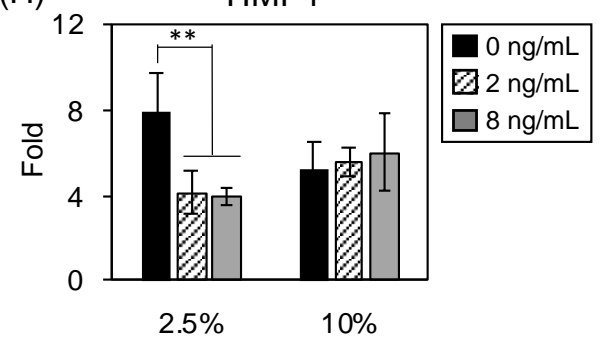

(J)

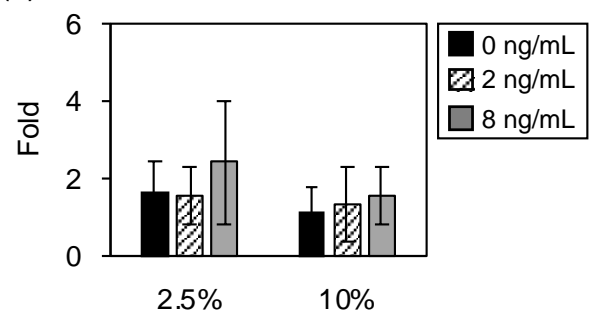

Figure 4. Relative gene expression of cocultures in $2.5 \%$ and $10 \%$ oxygen tension with TGF- $\beta 1$ stimulation $(0,2,8 \mathrm{ng} / \mathrm{mL})$ on day 14 . Each dataset represents the mean \pm standard deviation $(\mathrm{SD}, \mathrm{n}=6)$ from two independent experiments. Statistical significance was determined by the student's t-test with statistical significance of ${ }^{*} p<0.05,{ }^{* *} p<0.01,{ }^{* * *} p<0.001$, and ${ }^{* * *} p<0.0001$. 
The activation of HSCs is accompanied by the upregulation in the expression of fibrosis-related genes such as $\alpha$-SMA [23,24]. For $\alpha$-SMA gene expression, there was an approximately 2 -fold increase in the coculture from day 0 at $20 \%$ oxygenation tension to day 6 at both $10 \%$ and $2.5 \%$ oxygenation tensions. On day 6 , there was also a 1.2-fold upregulation in the $\alpha$-SMA gene expression when the coculture was exposed to $2.5 \%$ low oxygenation tension as compared to $10 \%$ (SI Figure S2D). Upon continuous hypoxic stimulation, on day 14 , there was a further 1.7 times increase in the $\alpha$-SMA gene expression for the cocultures in the $2.5 \%$ oxygen tension group compared to those in the $10 \%$ group (Figure 4A). However, $\alpha$-SMA immunostaining results revealed no significant differences between cocultures cultured under $2.5 \%$ and $10 \%$ oxygen tension (Figure $2 \mathrm{~B}$ ). These results showed that continuous hypoxia treatment alone at a low oxygen concentration of $2.5 \%$ possibly resulted in a slight overall increase in the activation of HSCs.

Fibrosis is characterized by the extensive deposition of ECM proteins, mainly collagen type I, III, and IV produced by HSCs $[1,18,23,25,26]$. The gene expression level of collagen type I was upregulated (about 1.6-fold higher) on day 6 for cultures subjected to $10 \%$ oxygenation tension as compared to day 0 cocultures; however, an increase in the collagen type I gene expression was not observed for the cocultures subjected to $2.5 \%$ oxygen tension (SI Figure S2D). On day 14, the collagen type I gene expression remained relatively constant for the $10 \%$ oxygenation tension group, but there was an approximately 2.3-fold increase in collagen type I gene expression for the $2.5 \%$ oxygenation tension group compared to day 6 , even though there was no significant difference in the collagen type I gene expression on day 14 in relation to the change in oxygen tension (Figure 4B). Furthermore, immunostaining results showed no significant differences in collagen type I expression in the $2.5 \%$ and $10 \%$ oxygen tension groups (Figure $2 \mathrm{~B}$ ).

Similar trends could also be observed in the collagen type III and IV gene expression results (Figure 4C and 4D). There were approximately 2 to 3 -fold increases in the gene expressions from day 0 control cocultures at $20 \%$ oxygenation tension to day 6 cocultures at both $10 \%$ and $2.5 \%$ oxygenation tensions. On day 6 , there was an approximate 1.5 -fold upregulation only in the collagen type IV gene expression when subjected to $2.5 \%$ oxygenation tension as compared to $10 \%$ (SI Figure S2D). Upon continuous hypoxic stimulation, on day 14, there was a 1.8-fold significant increase in the gene expression for collagen type IV in the cocultures under the $2.5 \%$ oxygen tension group compared to the $10 \%$ group (Figure $4 \mathrm{D}$ ). However, no significant change was found in the gene expression for collagen type I and III for the cocultures in both the $10 \%$ and $2.5 \%$ groups on day 14 (Figure $4 \mathrm{~B}$ and 4 C).

Platelet-derived growth factor gene, PDGF expression is upregulated during the proliferation of activated HSCs and is a marker for HSC proliferation [24,27]. The effect of varying oxygen tension on PDGF gene expression had been observed on day 6 as there was generally an increase in PDGF expression of about 2.5 -fold and 1.6-fold for the $2.5 \%$ and $10 \%$ oxygenation tension groups, respectively, as compared to $20 \%$ oxygen tension on day 0 (SI Figure S2D). However, this continual variation of oxygen tension did not bring further change in the PDGF gene expression on day 14 (Figure 4E).

CTGF gene expression levels were relatively stable on day 6 at both $2.5 \%$ and $10 \%$ oxygenation tensions (SI Figure S2D). There was no further significant change in CTGF gene expression under hypoxia treatment of $2.5 \%$ oxygen tension on day 14 ; however, culturing at $10 \%$ physiological oxygenation level increased the gene expression by about 3.0-fold compared to that on day 6 (Figure $4 \mathrm{~F})$.

For MMP2 gene expression, there was an approximately 6.0-fold increase in the $2.5 \%$ oxygenation tension group and an approximately 3.8 -fold significant increase in the $10 \%$ oxygenation tension group on day 6 compared to the $20 \%$ oxygenation tension control group on day 0 (SI Figure S2D). After prolonged hypoxia treatment at $2.5 \%$ oxygen tension, no significant influence on MMP2 gene expression could be observed on day 14 (Figure 4G). As for TIMP1 gene expression, with varying oxygen tension alone, there was an upregulation of about 2.8 times on day 6 in both the $10 \%$ and $2.5 \%$ oxygen tension cocultures than the control cocultures at $20 \%$ oxygenation on day 0 (SI Figure S2D). Upon prolonged hypoxia treatment at $2.5 \%$ oxygen tension, TIMP1 gene expression was 
upregulated and was about 1.5 -fold higher than $10 \%$ oxygen tension on day 14 (Figure $4 \mathrm{H}$ ) and was approximately 2.5 -fold higher than on day 6 . These results suggest that prolonged hypoxia treatment resulted in a promotion of collagen synthesis in the coculture tissues.

CYP1A1 and 1A2 in coculture were also enhanced by 2 times on day 6, while there were no differences on day 14 between $2.5 \%$ and $10 \%$ oxygen tension (SI Figure S2D, Figure 4I, and 4J).

\subsection{Coculture tissues were induced fibrogenesis by pro-fibrotic cytokine stimulation}

We stimulated cocultured liver tissues with the pro-fibrotic cytokine, TGF- $\beta 1$, for eight days from day 6 (Figure 1) and analyzed their function and the mRNA expression of key fibrotic-related and functional genes to characterize the response of HSCs in the cocultured liver tissues.

No particular effect by TGF- $\beta 1$ stimulation was observed on albumin secretion on day 14 for both the $10 \%$ and $2.5 \%$ oxygen tension groups (Figure $3 \mathrm{~A}$ ). CYP3A4 activity levels were also similar between day 6 and day 14 in the group without TGF- $\beta 1$ stimulation and at $2 \mathrm{ng} / \mathrm{mL}$ stimulation (Figure 3B and SI Figure S2C), while it decreased in $8 \mathrm{ng} / \mathrm{ml}$ of TGF- $\beta 1$ stimulation groups at both $2.5 \%$ and $10 \%$ oxygen tensions. CYP1A1 (Figure $4 \mathrm{I}$ ) and 1A2 (Figure 4J) were also unchanged by TGF$\beta 1$ stimulation, which suggested that there was no strong correlation or significant change in the respective CYP expressions related to the stimulus with TGF- $\beta 1$.

$\alpha$-SMA gene expressions were about 1.2-1.4 times enhanced by 2 and $8 \mathrm{ng} / \mathrm{ml}$ TGF- $\beta 1$ stimulation in $2.5 \%$ or $10 \%$ oxygen tension than the group without TGF- $\beta 1$ stimulation (Figure $4 \mathrm{~A}$ ). Collagen type I gene, Col1A1 expression, had a concentration-dependent change with TGF- $\beta 1$ on day 14 (Figure 4B). It enhanced about 1.6 and 2.0 -fold with $2 \mathrm{ng} / \mathrm{ml}$ stimulation at $2.5 \%$ and $10 \%$ oxygen tension, respectively. It also increased by about 2.8 - and 2.3 -fold with $8 \mathrm{ng} / \mathrm{ml}$ stimulation at $2.5 \%$ and $10 \%$ oxygen tension, respectively, compared to the absence of TGF- $\beta 1$ stimulation. Immunostaining results also showed a higher expression of collagen type I at $8 \mathrm{ng} / \mathrm{ml}$ (Figure 2). Collagen type III and IV gene, Col3A1 and Col4A1, also tended to increase by TGF- $\beta 1$ stimulation, while there were no statistical differences (Figure 4C and 4D). These results illustrated that higher TGF- $\beta 1$ stimulation concentrations resulted in collagen fiber synthesis and collagen accumulation in the cocultured liver tissues.

PDGF had no significant difference regarding the effect of TGF- $\beta 1$ stimulation at both 2 and 8 $\mathrm{ng} / \mathrm{ml}$ of TGF- $\beta 1$ stimulation (Figure $4 \mathrm{E}$ ). Although there was an overall increase in PDGF gene expression (of at least 1.3-fold) sustained throughout from day 6 to day 14 compared to day 0 , the expression was decreased on day 14 compared to day 6 . The connective tissue growth factor gene expression, CTGF, was slightly downregulated at $8 \mathrm{ng} / \mathrm{ml}$ TGF- $\beta 1$ stimulation under $2.5 \%$ and $10 \%$ oxygen tension (Figure 4F). Matrix metalloproteinase 2, MMP2, gene expression on day 14 increased about 1.5-fold when the cocultured liver tissues were induced with $8 \mathrm{ng} / \mathrm{ml}$ of TGF- $\beta 1$ at $2.5 \%$ and $10 \%$ oxygen tension as compared to cocultures that were without any TGF- $\beta 1$ stimulation (Figure $4 \mathrm{G})$. As for the tissue inhibitor of metalloproteinases 1 gene, TIMP1, there was no significant difference except for the group without TGF- $\beta 1$ stimulation on day 14 (Figure $4 \mathrm{H})$, and the expression level was about 2-fold increased from day 6 to day 14 (SI Figure S2D).

\section{Discussion}

Over the years, scientific development has focused on establishing relevant anti-fibrotic strategies that target the HSCs [28]. However, such 2D monoculture models have been proven to be inefficient in developing appropriate treatments for control of liver damage as the mechanisms by which HSCs are mediated through culture might differ considerably despite the application of different HSC culture models of varying complexity [29-31]. Thus, much needed to be incorporated to justify the treatment of chronic liver conditions. Research showed a significant interaction between HSCs, biomechanics, cell matrix, hepatocytes, and other non-parenchymal cells that enhance and promote specific liver cell functions [28]. As such, the development of 3D in vitro models that could recreate the liver microenvironment is required and could be linked to the objectives of developing novel anti-fibrogenic compounds. 
We demonstrated the liver coculture system of hepatocyte and non-parenchymal liver cells, including HSCs and LSECs, for liver fibrosis studies. We intended to mimic the in vivo microenvironment for liver fibrosis studies. First, we developed the hierarchical cocultured liver tissues inspired by the microstructure surrounding the hepatocytes. We seeded hepatocytes, HSCs, and LSECs, one on top of the other on oxygen-permeable PDMS membranes, facilitating oxygen diffusion to the culture system (Figure 1).

Such a PDMS-based culture system, therefore, enables the supply of sufficient oxygen content to the tissue, which leads to maintaining viability and promoting the healthy growth of liver tissues to develop high-density 3D cell culture [14,32-34]. As cultured primary rat hepatocytes exhibit high oxygen consumption [35], the PDMS culture plate allows the establishment of a hierarchical coculture model that mimics the in vivo liver physiology as primary hepatocytes could be easily cocultured with other non-parenchymal cells in a 3D manner or structure using this platform [14,32]. On the contrary, conventional tissue culture polystyrene plates could not support this kind of coculture due to insufficient oxygen being supplied to the tissues to maintain viability and growth [36]. Other coculture systems or studies have also encountered the limited formation of cell-cell contacts [37-39], and oxygen shortage could limit the thick tissue formation as well as the hepatic functions of the cocultures [40]. Based on our culture system, we characterized the cocultured liver tissue functions such as albumin production, metabolic enzyme activity, and gene expression. Cocultures maintained their hepatic functions better than monocultures, as there was an enhancement in albumin protein synthesis and activity of rat drug metabolism enzyme, CYP3A4 (SI Figure S2). It has been reported that the cell-cell interaction enhanced hepatic function by promoting the cell-derived growth factor or ECM production [41]. Thus, the studied cocultured tissues might promote tissue formation with enhanced cell matrix production.

Since PDMS-based culture enables direct oxygenation to the cultured cells in different oxygen tensions without oxygen shortage for cellular respiration [33,34], we varied the culture atmosphere from $20 \%$ to $10 \%$ and $2.5 \%$ oxygen tension, considering normoxia and hypoxia in vivo (Figure 1 ). Albumin production decreased under $2.5 \%$ hypoxic condition, while CYP3A4 activity was unchanged (Figure 3 and SI Figure S2C). The oxygen supply similar to normoxia in vivo enhances multiple hepatocyte inductive factors that might promote albumin production in liver tissues [42]. CYP P450 activity is influenced by oxygen gradient and low oxygen regions. Therefore, CYP P450 activity in the central vein is higher in vivo compared to the higher oxygen area, the portal vein. CYP3A4 activity showed oxygen tension-dependent behavior thanks to the continuous oxygenation even in hypoxic oxygen tension $[43,44]$.

The cocultured liver tissue was then applied to the examination of further fibrogenesis studies. During chronic liver injury, the increased accumulation of ECM, which is generally rich in both type I and III collagen, results in liver fibrosis and scar deposition [24,26,45,46]. During fibrogenesis, HSCs, which are localized in the perisinusoidal space between the sinusoidal endothelial cells and the hepatocytes, transdifferentiate to myofibroblasts with their activation [2,45]. A wide range of collective and individual signals, as well as intracellular occurrences, could lead to HSC activation. Some of the significant proliferative and fibrogenic pathways regulating the activation of HSCs include cytokines such as the connective tissue growth factor (CTGF), platelet-derived growth factor (PDGF), transforming growth factor- $\beta$ (TGF- $\beta$ ) [9], and the vascular endothelial growth factor (VEGF) [45]. TGF- $\beta$ is recognized as the most potent fibrogenic cytokine, which, in a quiescent form, is produced by several cell populations found in the liver [47]. The phosphorylation of the type I receptor, along with TGF- $\beta$ binding, is known to induce phosphorylation of downstream SMAD proteins, primarily of SMAD3 [45]. When SMAD3 is activated during HSC activation, it elevates the transcription of type III and type I collagen [9,48,49]. Hypoxia is another commonly regarded environmental stress factor that is closely linked to several pathological and physiological conditions like fibrogenesis, according to Shi et al. [8]. Liver injuries occur in the hypoxic regions, and HSC activation is considered the critical aspect of liver fibrogenesis [8].

We observed an upregulation of the fibrosis-related biomarkers and HSC activation markers such as $\alpha$-SMA [24] when we subjected the model to a hypoxic condition and the pro-fibrogenic 
cytokine, TGF- $\beta 1$ (Figure 4). Interestingly, our results showed that continuous hypoxia treatment alone at a low oxygen tension of $2.5 \%$ could result in an overall increase in the activation of HSCs, as observed with the rise in $\alpha$-SMA gene expression in the cocultures (SI Figure S2D and Figure 4). Furthermore, when stimulated with TGF- $\beta 1$, there was a further increase not only in the $\alpha$-SMA gene expression but also in other fibrosis biomarkers such as collagen type I, III, and IV $[1,18,25]$ that are commonly found in diseased livers, which indicates that TGF- $\beta 1$ had a substantial pro-fibrogenic effect on the coculture system. These results demonstrated that low oxygen tension, coupled with TGF- $\beta$ stimulation, had resulted in a greater extent of HSC activation in vitro. Further stimulation by TGF- $\beta$ should promote their fibrogenesis with excessive collagen production and accumulation.

Based on our results, we also noted that the PDGF gene expression, a marker for activated HSC proliferation $[2,24,45,50]$, might depend on varying oxygen tension and not on TGF- $\beta 1$ stimulation, with an upregulation of the gene observed throughout the whole coculture period. This suggests that there was a proliferation of activated HSCs in the coculture in vitro.

TIMP1 is responsible for the inhibition of MMPs (which degrades ECM) [1,51-54], thus leading to a net accumulation of ECM in fibrotic livers. TIMP1 gene expression was increased after continuous culture under both oxygen tensions. The highest expression was observed for the $2.5 \%$ oxygen tension group without TGF- $\beta 1$ stimulation. This increase in TIMP1 gene expression could explain the accumulation of collagen content, such as collagen type I and III, during the development of fibrogenesis that might be occurring in the liver tissue cocultures.

We also found significant upregulation of MMP2 in our cocultures when induced fibrogenesis with TGF- $\beta 1$ (Figure $4 \mathrm{G}$ ), which is a phenomenon that is also observed and highly up-promoted during liver fibrosis as MMP2 is involved in ECM remodeling [52,55] and causes degradation of collagen type IV. However, we detected a rise in collagen type IV gene expression. This might be because the tissues were in early fibrogenesis as stimulated by inflammatory signals. Hence, the degradation effect of collagen type IV due to MMP2 might be masked by the increase in collagen type IV in the tissues.

MMP1 decrease causes collagen type I and type III accumulation in the tissues [56-58]. MMP1 gene expression was not stable in this culture but was generally lower in $2.5 \%$ than $10 \%$ oxygen tension (data not shown), explaining the increase in collagen type I and III in the cocultured tissues.

Albumin protein secretion, expression of genes encoding for CYP enzymes, and its activity were studied to evaluate the possible effect of varying oxygen tension and TGF- $\beta 1$ stimulation on the functional characteristics of the cocultured liver tissue. As shown in the results, there was no convincing evidence that varying TGF- $\beta 1$ stimulation concentrations would affect the rat albumin secretion and expression of rat drug-metabolism enzymes, such as CYP1A1/1A2/3A4, as there was no significant decrease in their expressions after stimulating with the pro-fibrotic TGF- $\beta 1$ cytokine. This indicates rat hepatocytes' functionality in the cocultures; hence, the tissues' hepatic function was not affected because of the relatively constant gene expression and maintenance of crucial rat functionality indexes. Conversely, varying oxygen tension at a higher level could lead to enhanced hepatic functionality as observed with the higher albumin secretion in the $10 \%$ physiological oxygenation tension cocultures compared to the $2.5 \%$ hypoxic oxygenation tension cocultures.

Overall, through stable culturing of the major heterogeneous cells that make up the liver, the system becomes more stable than the hepatocyte monoculture. In particular, by administering inflammatory cytokines and intentionally blocking oxygen supply to cells, we have observed the activation of hepatic stellate cells and the enhanced synthesis and accumulation of collagen fibers in the culture system, as seen in the early stages of liver fibrosis. Although further study about the influence of cellular-derived factors should be examined, this culture system holds great promise and could be used not only to observe the effects and side effects of drugs but also to reproduce the liver fibrosis phenomenon, which is attracting attention as a chronic liver disease mechanism under culture conditions. 


\section{Conclusions}

We developed multilayer cocultured liver tissues with hepatocyte, sinusoidal endothelial cells, and hepatic stellate cells to demonstrate the induction of liver inflammation for liver fibrosis models in vitro. Our cocultured liver tissues maintained their hepatic functions and showed their utility and capability as a physiologically relevant disease model to respond to the pro-fibrotic factor, TGF- $\beta 1$, stimulation. Although the collagen synthesis and degradation-related gene expression were not consistent, hypoxia-induced hepatic disorder and TGF- $\beta 1$-dependent fibrogenesis behavior in gene expressions were observed. This culture system demonstrated the potential application to examine the molecular mechanisms and pathogenesis of liver fibrosis, cellular interaction, and unknown microenvironmental factors, which would lead to the development of novel anti-fibrogenic strategies and potent drugs to stimulate liver recovery. Further studies using a combination of human cells, including immune cells, are expected.

Supplementary Materials: The following are available online at www.mdpi.com/xxx/s1, Figure S1: Morphological changes from day 0 to day 14. Figure S2: Hepatic functions of cocultured liver tissues. Figure S3: Hematoxylin and eosin ( $\mathrm{H} \& \mathrm{E}$ ) staining of vertical hepatic tissue coculture sections in $2.5 \%$ and $10 \%$ oxygen tension on day 14 .

Author Contributions: Conceptualization, Y.S., M.S., and Q.Y.L.; methodology, Y.S., M.S., and Q.Y.L; validation, Q.Y.L and F.G.T.; formal analysis, Q.Y.L., F.G.T., and M.S.; data curation, Q.Y.L., F.G.T., and M.S.; writingoriginal draft preparation, Q.Y.L., F.G.T., and M.S.; writing-review and editing, Q.Y.L., F.G.T., M.S., and Y.S.; supervision, Y.S. and M.S.; project administration, Y.S. and M.S.; funding acquisition, Y.S. and M.S. All authors have read and agreed to the published version of the manuscript.

Funding: This research was funded by the Japanese Agency for Medical Research and Development (Grant No. 18bm0704007h0003 and 17be0304201h0001) and Japan Bio Products Co., Ltd.

Acknowledgments: We would like to especially thank Dr. Hiroyuki Miyazaki, from Japan Bio Products Co., Ltd., for his technical advice.

Conflicts of Interest: The authors declare no conflict of interest. The funders had no role in the design of the study; in the collection, analyses, or interpretation of data; in the writing of the manuscript, or in the decision to publish the results. 


\section{Supplementary Materials}
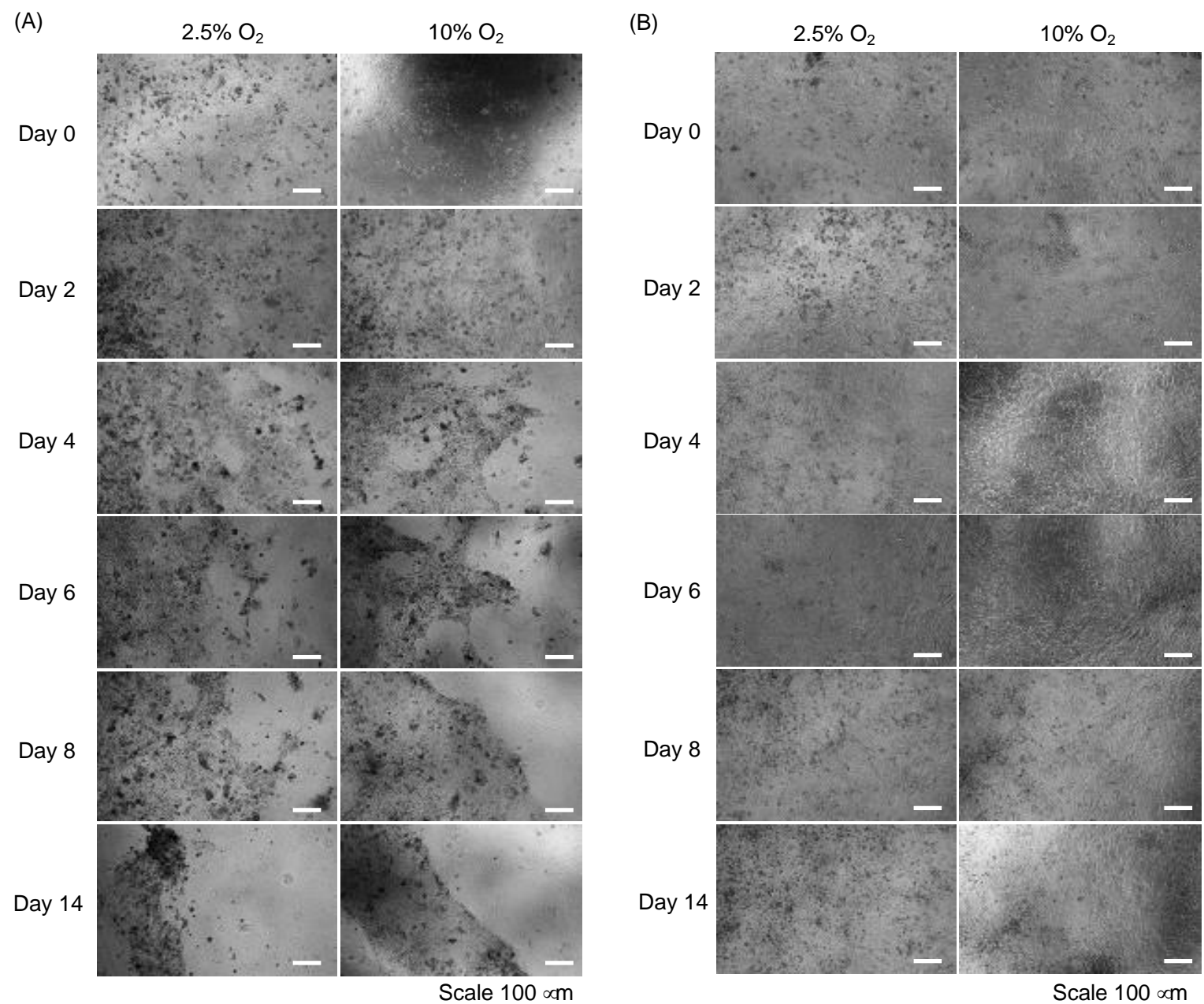

Supplementary Figure S1. Morphological changes from day 0 to day 14. (A) Monoculture, (B) Coculture. 
(A)

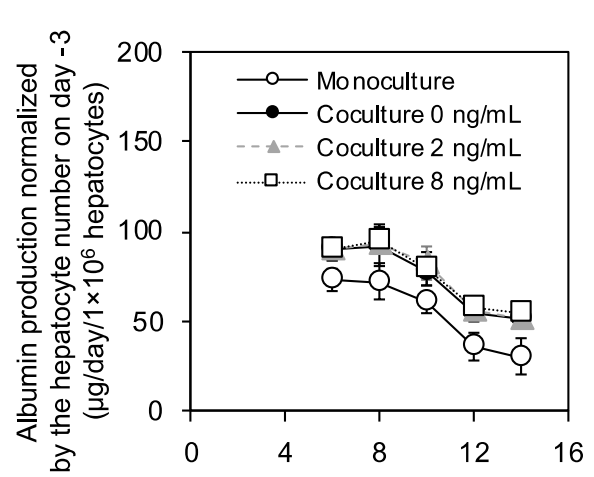

(C)

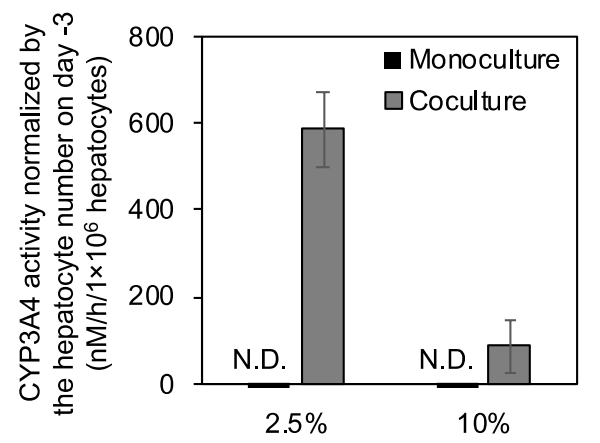

(B)

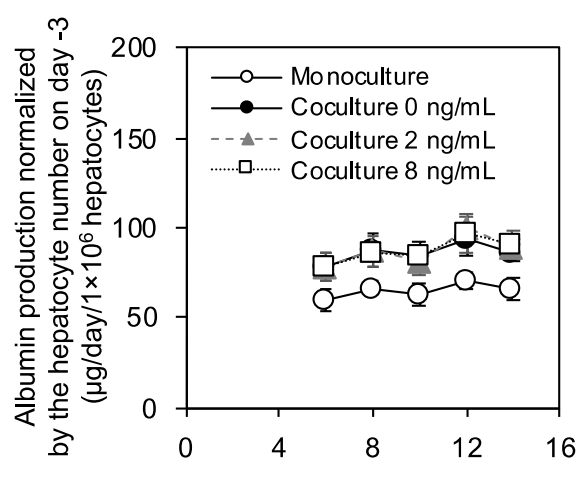

(D)

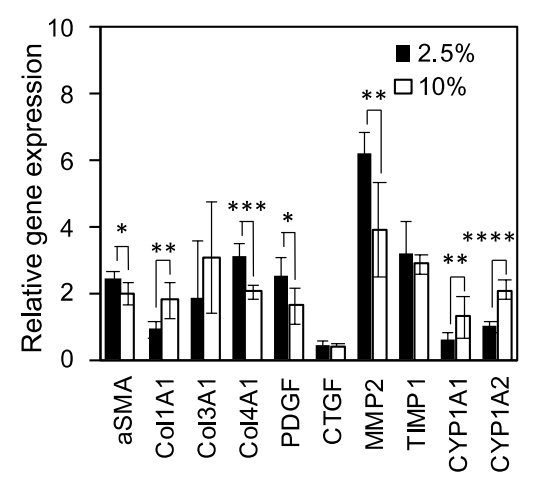

Supplementary Figure S2. Hepatic functions of cocultured liver tissues. (A, B) Albumin functional assay of monocultures and cocultures with TGF- $\beta 1$ stimulation $(0,2,8 \mathrm{ng} / \mathrm{mL})$ in $2.5 \%$ and $10 \%$ oxygen tension, respectively. (C) CYP3A4 functional assay of monocultures and cocultures in $2.5 \%$ and $10 \%$ oxygen tension on day 6 . (D) Relative gene expression of cocultures in $2.5 \%$ and $10 \%$ oxygen tension on day 6 .

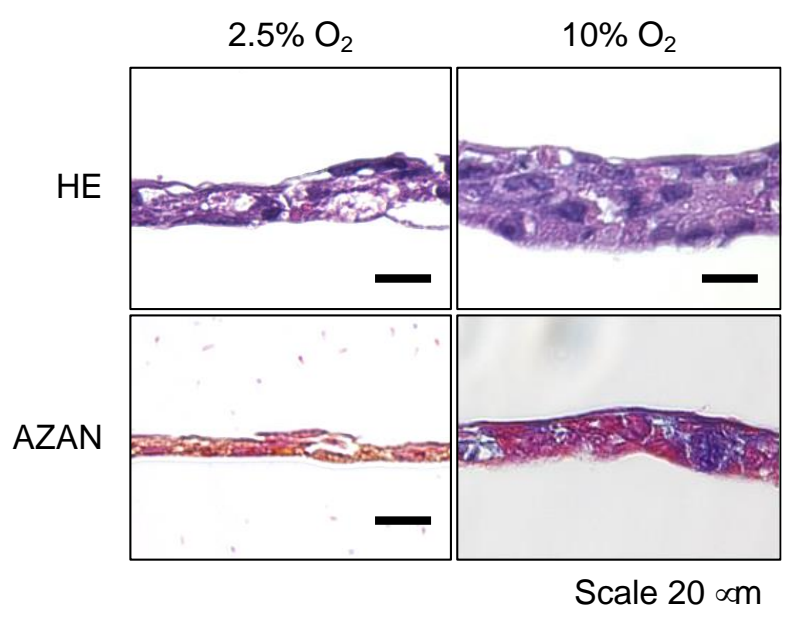

Supplementary Figure S3. Hematoxylin and eosin (H \& E) staining of vertical hepatic tissue coculture sections in $2.5 \%$ and $10 \%$ oxygen tension on day 14 . 


\section{References}

1. Robert, S.; Gicquel, T.; Bodin, A.; Lagente, V.; Boichot, E. Characterization of the MMP/TIMP imbalance and collagen production induced by IL-1 $\beta$ or TNF- $\alpha$ release from human hepatic stellate cells. PLOS ONE 2016, 11, 1-14, doi:10.1371/journal.pone.0153118.

2. Puche, J.E.; Saiman, Y.; Friedman, S.L. Hepatic stellate cells and liver fibrosis. Compr. Physiol. 2013.

3. Friedman, S.L.; Sheppard, D.; Duffield, J.S.; Violette, S. Therapy for fibrotic diseases: nearing the starting line. Sci. Transl. Med. 2013, 5, 167sr1--167sr1.

4. Schuppan, D.; Kim, Y.O. Evolving therapies for liver fibrosis. J. Clin. Invest. 2013, 123, 18871901.

5. Greek, R.; Menache, A. Systematic reviews of animal models: methodology versus epistemology. Int. J. Med. Sci. 2013, 10, 206.

6. Schuster, D.; Laggner, C.; Langer, T. Why drugs fail-a study on side effects in new chemical entities. Curr. Pharm. Des. 2005, 11, 3545-3559.

7. Bhandari, R.N.B.; Riccalton, L.A.; Lewis, A.L.; Fry, J.R.; Hammond, A.H.; Tendler, S.J.B.; Shakesheff, K.M. Liver Tissue Engineering: A Role for Co-culture Systems in Modifying Hepatocyte Function and Viability. Tissue Eng. 2001, 7, 345-357, doi:10.1089/10763270152044206.

8. Shi, Y.F.; Fong, C.C.; Zhang, Q.; Cheung, P.Y.; Tzang, C.H.; Wu, R.S.S.; Yang, M. Hypoxia induces the activation of human hepatic stellate cells LX-2 through TGF- $\beta$ signaling pathway. FEBS Lett. 2007, 581, 203-210, doi:10.1016/j.febslet.2006.12.010.

9. Xu, F.; Liu, C.; Zhou, D.; Zhang, L. TGF- $\beta / S M A D$ Pathway and Its Regulation in Hepatic Fibrosis. J. Histochem. Cytochem. 2016, 64, 157-167.

10. Bhadriraju, K.; Chen, C.S. Engineering cellular microenvironments to improve cell-based drug testing. Drug Discov. Today 2002, 7, 612-620.

11. Breslin, S.; O'Driscoll, L. Three-dimensional cell culture: the missing link in drug discovery. Drug Discov. Today 2013, 18, 240-249.

12. Breslin, S.; O'Driscoll, L. The relevance of using 3D cell cultures, in addition to 2D monolayer cultures, when evaluating breast cancer drug sensitivity and resistance. Oncotarget 2016, 7, 45745.

13. Bell, C.C.; Hendriks, D.F.G.; Moro, S.M.L.; Ellis, E.; Walsh, J.; Renblom, A.; Fredriksson Puigvert, L.; Dankers, A.C.A.; Jacobs, F.; Snoeys, J.; et al. Characterization of primary human hepatocyte spheroids as a model system for drug-induced liver injury, liver function and disease. Sci. Rep. 2016, 6, 25187, doi:10.1038/srep25187.

14. Xiao, W.; Perry, G.; Komori, K.; Sakai, Y. New physiologically-relevant liver tissue model based on hierarchically cocultured primary rat hepatocytes with liver endothelial cells. Integr Biol 2015, 7, 1412-1422, doi:10.1039/C5IB00170F.

15. Bhatia, S.N.; Balis, U.J.; Yarmush, M.L.; Toner, M. Probing heterotypic cell interactions: hepatocyte function in microfabricated co-cultures. J. Biomater. Sci. Polym. Ed. 1998, 9, 11371160.

16. Bhatia, S.N.; Balis, U.J.; Yarmush, M.L.; Toner, M. Effect of cell--cell interactions in preservation of cellular phenotype: cocultivation of hepatocytes and nonparenchymal cells. FASEB J. 1999, 13, 1883-1900. 
17. Du, Y.; Li, N.; Yang, H.; Luo, C.; Gong, Y.; Tong, C.; Gao, Y.; Lü, S.; Long, M. Mimicking liver sinusoidal structures and functions using a 3D-configured microfluidic chip. Lab. Chip 2017, 17, 782-794.

18. Gressner, A.M.; Weiskirchen, R. Modern pathogenetic concepts of liver fibrosis suggest stellate cells and TGF- $\beta$ as major players and therapeutic targets. J. Cell. Mol. Med. 2006, 10, 76-99.

19. Seglen, P.O. Preparation of isolated rat liver cells. In Methods in cell biology; Elsevier, 1976 ; Vol. 13, pp. 29-83.

20. Xu, L.; Hui, A.Y.; Albanis, E.; Arthur, M.J.; O’byrne, S.M.; Blaner, W.S.; Mukherjee, P.; Friedman, S.L.; Eng, F.J. Human hepatic stellate cell lines, LX-1 and LX-2: new tools for analysis of hepatic fibrosis. Gut 2005, 54, 142-151.

21. Yan, H.-M.; Ramachandran, A.; Bajt, M.L.; Lemasters, J.J.; Jaeschke, H. The oxygen tension modulates acetaminophen-induced mitochondrial oxidant stress and cell injury in cultured hepatocytes. Toxicol. Sci. 2010, 117, 515-523.

22. Hanada, S.; Kayano, H.; Jiang, J.; Kojima, N.; Miyajima, A.; Sakoda, A.; Sakai, Y. Enhanced in vitro maturation of subcultivated fetal human hepatocytes in three dimensional culture using poly-L-lactic acid scaffolds in the presence of oncostatin M. Int. J. Artif. Organs 2003, 26, 943951.

23. Kisseleva, T.; Brenner, D.A. Hepatic stellate cells and the reversal of fibrosis. J. Gastroenterol. Hepatol. Aust. 2006, 21, doi:10.1111/j.1440-1746.2006.04584.x.

24. Moreira, R.K. Hepatic Stellate Cells and Liver Fibrosis. Arch Pathol Lab Med-Vol 2007, 131, 1728-1734, doi:10.1002/cphy.c120035.

25. Urushiyama, H.; Terasaki, Y.; Nagasaka, S.; Terasaki, M.; Kunugi, S.; Nagase, T.; Fukuda, Y.; Shimizu, A. Role of $\alpha 1$ and $\alpha 2$ chains of type IV collagen in early fibrotic lesions of idiopathic interstitial pneumonias and migration of lung fibroblasts. Lab. Invest. 2015, 95, 872.

26. Bataller, R.; Brenner, D. Liver fibrosis. J. Clin. Invest. 2005, 115, 209-218, doi:10.1172/JCI200524282.The.

27. Friedman, S.L.; Arthur, M.J. Activation of cultured rat hepatic lipocytes by Kupffer cell conditioned medium. Direct enhancement of matrix synthesis and stimulation of cell proliferation via induction of platelet-derived growth factor receptors. J. Clin. Invest. 1989, 84, 1780-1785.

28. Mazza, G.; Al-Akkad, W.; Rombouts, K. Engineering in vitro models of hepatofibrogenesis. Adv. Drug Deliv. Rev. 2017, 121, 147-157, doi:10.1016/j.addr.2017.05.018.

29. van Grunsven, L.A. 3D in vitro models of liver fibrosis. Adv. Drug Deliv. Rev. 2017, 121, 133146, doi:10.1016/j.addr.2017.07.004.

30. Rombouts, K. Hepatic stellate cell culture models. In Stellate Cells in Health and Disease; Elsevier, 2015; pp. 15-27.

31. Imai, K.; Sato, T.; Senoo, H. Adhesion between cells and extracellular matrix with special reference to hepatic stellate cell adhesion to three-dimensional collagen fibers. Cell Struct. Funct. 2000, 25, 329-336.

32. Evenou, F.; Hamon, M.; Fujii, T.; Takeuchi, S.; Sakai, Y. Gas-permeable membranes and coculture with fibroblasts enable high-density hepatocyte culture as multilayered liver tissues. Biotechnol. Prog. 2011, 27, 1146-1153. 
33. Xiao, W.; Kodama, M.; Komori, K.; Sakai, Y. Oxygen-permeable membrane-based direct oxygenation remarkably enhances functions and gene expressions of rat hepatocytes in both 3D and sandwich cultures. Biochem. Eng. J. 2014, 91, 99-109, doi:10.1016/j.bej.2014.08.005.

34. Xiao, W.; Shinohara, M.; Komori, K.; Sakai, Y.; Matsui, H.; Osada, T. The importance of physiological oxygen concentrations in the sandwich cultures of rat hepatocytes on gaspermeable membranes. Biotechnol. Prog. 2014, 30, 1401-1410, doi:10.1002/btpr.1954.

35. Matsui, H.; Osada, T.; Moroshita, Y.; Sekijima, M.; Fujii, T.; Takeuchi, S.; Sakai, Y. Rapid and enhanced repolarization in sandwich-cultured hepatocytes on an oxygen-permeable membrane. Biochem. Eng. J. 2010, 52, 255-262.

36. Nahmias, Y.; Casali, M.; Barbe, L.; Berthiaume, F.; Yarmush, M.L. Liver endothelial cells promote LDL-R expression and the uptake of HCV-like particles in primary rat and human hepatocytes. Hepatology 2006, 43, 257-265.

37. Bhatia, S.N.; Yarmush, M.L.; Toner, M. Controlling cell interactions by micropatterning in cocultures: Hepatocytes and 3 T3 fibroblasts. J. Biomed. Mater. Res. Off. J. Soc. Biomater. Jpn. Soc. Biomater. 1997, 34, 189-199.

38. Lu, H.-F.; Chua, K.-N.; Zhang, P.-C.; Lim, W.-S.; Ramakrishna, S.; Leong, K.W.; Mao, H.-Q. Three-dimensional co-culture of rat hepatocyte spheroids and NIH/3T3 fibroblasts enhances hepatocyte functional maintenance. Acta Biomater. 2005, 1, 399-410.

39. Mesnil, M.; Fraslin, J.-M.; Piccoli, C.; Yamasaki, H.; Guguen-Guillouzo, C. Cell contact but not junctional communication (dye coupling) with biliary epithelial cells is required for hepatocytes to maintain differentiated functions. Exp. Cell Res. 1987, 173, 524-533.

40. Ishihara, K.; Mizumoto, H.; Nakazawa, K.; Kajiwara, T.; Funatsu, K. Formation of a sheetshaped organoid using rat primary hepatocytes for long-term maintenance of liver-specific functions. Int. J. Artif. Organs 2006, 29, 318-328.

41. Auth, M.K.H.; Okamoto, M.; Ishida, Y.; Keogh, A.; Auth, S.H.G.; Gerlach, J.; Encke, A.; McMaster, P.; Strain, A.J. Maintained function of primary human hepatocytes by cellular interactions in coculture: implications for liver support systems. Transpl. Int. 1998, 11, S439-S443.

42. Haque, A.; Gheibi, P.; Gao, Y.; Foster, E.; Son, K.J.; You, J.; Stybayeva, G.; Patel, D.; Revzin, A. Cell biology is different in small volumes: endogenous signals shape phenotype of primary hepatocytes cultured in microfluidic channels. Sci. Rep. 2016, 6, 33980.

43. Guo, R.; Xu, X.; Lu, Y.; Xie, X. Physiological oxygen tension reduces hepatocyte dedifferentiation in in vitro culture. Sci. Rep. 2017, 7, 1-9.

44. Scheidecker, B.; Shinohara, M.; Sugimoto, M.; Danoy, M.; Nishikawa, M.; Sakai, Y. Induction of in vitro Metabolic Zonation in Primary Hepatocytes Requires Both Near-Physiological Oxygen Concentration and Flux. Front. Bioeng. Biotechnol. 2020, 8, 524.

45. Tsuchida, T.; Friedman, S.L. Mechanisms of hepatic stellate cell activation. Nat. Rev. Gastroenterol. Hepatol. 2017, 14, 397-411, doi:10.1038/nrgastro.2017.38.

46. Koyama, Y.; Brenner, D.A. Liver inflammation and fibrosis. J. Clin. Invest. 2017, 127, 55-64.

47. Hellerbrand, C.; Stefanovic, B.; Giordano, F.; Burchardt, E.R.; Brenner, D.A. The role of TGFß1 in initiating hepatic stellate cell activation in vivo. J. Hepatol. 1999, 30, 77-87.

48. Breitkopf, K.; Godoy, P.; Ciuclan, L.; Singer, M. V; Dooley, S. TGF- $\beta /$ Smad signaling in the injured liver. Z. Für Gastroenterol. 2006, 44, 57-66. 
49. Friedman, S.L. Hepatic stellate cells: protean, multifunctional, and enigmatic cells of the liver. Physiol. Rev. 2008, 88, 125-172.

50. Hernandez-Gea, V.; Friedman, S.L. Pathogenesis of Liver Fibrosis. Annu. Rev. Pathol. Mech. Dis. 2011, 6, 425-456, doi:10.1146/annurev-pathol-011110-130246.

51. Thiele, N.D.; Wirth, J.W.; Steins, D.; Koop, A.C.; Ittrich, H.; Lohse, A.W.; Kluwe, J. TIMP-1 is upregulated, but not essential in hepatic fibrogenesis and carcinogenesis in mice. Sci. Rep. 2017, 7, 714, doi:10.1038/s41598-017-00671-1.

52. Hemmann, S.; Graf, J.; Roderfeld, M.; Roeb, E. Expression of MMPs and TIMPs in liver fibrosis - a systematic review with special emphasis on anti-fibrotic strategies. J. Hepatol. 2007, 46, 955975, doi:10.1016/j.jhep.2007.02.003.

53. Arpino, V.; Brock, M.; Gill, S.E. The role of TIMPs in regulation of extracellular matrix proteolysis. Matrix Biol. 2015, 44-46, 247-254, doi:10.1016/j.matbio.2015.03.005.

54. Yoshiji, H.; Kuriyama, S.; Miyamoto, Y.; Thorgeirsson, U.P.; Gomez, D.E.; Kawata, M.; Yoshii, J.; Ikenaka, Y.; Noguchi, R.; Tsujinoue, H.; et al. Tissue inhibitor of metalloproteinases-1 promotes liver fibrosis development in a transgenic mouse model. Hepatology 2000, 32, 12481254, doi:10.1053/jhep.2000.20521.

55. Duarte, S.; Baber, J.; Fujii, T.; Coito, A.J. Matrix metalloproteinases in liver injury, repair and fibrosis. Matrix Biol. 2015, 44, 147-156.

56. Arthur, M.J.P. Degradation of matrix proteins in liver fibrosis. Pathol.-Res. Pract. 1994, 190, 825833.

57. Arthur, M.J.P. Role of Ito cells in the degradation of matrix in liver. J. Gastroenterol. Hepatol. 1995, 10, S57--S62.

58. Arthur, M.J. Collagenases and liver fibrosis. J. Hepatol. 1995, 22, 43-48. 